\title{
Comparison of Mini-Laparoscopic and Conventional Laparoscopic Surgery for Tubal Ligation
}

\author{
Servet GENCDAL ${ }^{1}$, Emre EKMEKCI ${ }^{2}$
}

Izmir, Turkey

\section{ABSTRACT}

OBJECTIVE: To compare the intraoperative characteristics and postoperative results of mini laparoscopic and conventional laparoscopic surgeries performed for surgical sterilization.

STUDY DESIGN: This retrospective study was conducted to compare the conventional and mini laparoscopic tubal ligation for surgical tubal sterilization. In total of 39 women, 22 in the conventional laparoscopy and 17 in the mini laparoscopic surgery group participated in the study. The main outcome measures were total operation time, amount of bleeding, intraoperative complications, skin scar formation with patient scale and observer scale and length of hospital stay.

RESULTS: Demographical findings did not differ between the two groups. Similarly, rates of intraoperative complications, conversion to laparotomy, length of hospital stay, pre and postoperative hematocrit levels were not significantly different between the groups. Both patient and observer POSAS scores were better in mini laparoscopic surgery group.

CONCLUSION: Mini laparoscopic surgery seems a safe and feasible alternative to conventional laparoscopy for surgical tubal sterilization.

Keywords: Mini-Laparoscopy, Laparoscopy, Tubal ligation, Surgical sterilization

Gynecol Obstet Reprod Med 2018;24(3):139-142

\section{Introduction}

Tubal ligation is sterilization of women. In tubal sterilization, fallopian tubes are removed or cut and tied with special thread, closed shut with bands or clips, sealed with an electric current, or blocked with scar tissue formed by small implants (1). Tubal ligation is a permanent method of birth control offering immediate and highly effective protection against un-

\footnotetext{
${ }^{1}$ Izmir Katip Celebi University Atatürk Education and Research Hospital Department of Obstetrics and Gynecology, Izmir

${ }^{2}$ University of Health Sciences Sanlurfa Education and Research Hospital Department of Perinatology, Sanluurfa

Address of Correspondence: Servet Gencdal

Izmir Katip Celebi University Atatürk

Education and Research Hospital

Department of Obstetrics and

Gynecology, 35360 Izmir, Turkey

servetgencdal@hotmail.com

Submitted for Publication:

04.05 .2018

Accepted for Publication:

16.09.2018
}

\begin{tabular}{|c|c|}
\hline & Access this article online \\
\hline $\begin{array}{c}\text { Quick Response Code: } \\
\text { Website: www.gorm.com.tr } \\
\end{array}$ & \begin{tabular}{l} 
e- mail: info@gorm.com.tr \\
\cline { 2 - 3 }
\end{tabular} \\
\hline
\end{tabular}

How to cite this article: Gencdal S. and Ekmekci E. Comparison of MiniLaparoscopic and Conventional Laparoscopic Surgery for Tubal Ligation. Gynecol Obstet Reprod Med 2018;24(3):139-142 expected pregnancy. However, it is a surgical procedure and therefore carries the risks associated with surgical intervention and offers no protection against sexually-transmitted diseases. Laparoscopic surgery is minimally invasive surgery that is associated with several advantages over traditional open surgery. Less post-operative pain and disability, a shorter hospital stay, and a quicker recovery period are major advantages that laparoscopic surgery offers when compared with traditional operations. Due to the rapid development of modern laparoscopic surgery, surgeons now have more opportunities to use minimally invasive techniques for almost all kinds of surgeries. Laparoscopic sterilization techniques are highly effective. Depending on how the fallopian tubes are closed, pregnancy rates within 10 years after the procedure range from $18 / 1000$ women to $37 / 1000$ women (1). Mini laparoscopy is defined as surgery with instruments $2-5 \mathrm{~mm}$ in diameter, with the only possible exception of using larger diameter optics at the umbilicus (2). During the last years, several mini-laparoscopic procedures have been successfully performed in various surgical fields (3). In addition, these minimally invasive surgical techniques are frequently preferred to ensure better cosmetic results. However, to date, no comparative study exists of mini-laparoscopic surgery (MLS) versus conventional laparoscopic surgery (CLS) for tubal ligation.

The aim of our study was to compare intra and postoperative results of these two minimally invasive approaches. 


\section{Material and Method}

This retrospective study was conducted at Izmir Katip Celebi University Ataturk Education and Research Hospital between January 2015 and December 2015 (project identification number: 3-T-02). Informed consent was obtained from all patients. Thirty-nine consecutive patients who needed laparoscopic surgery for surgical tubal sterilization were enrolled in the study. All patients were called to the hospital by telephone for skin scar formation assessment using the patient scale and observer scale (POSAS). The POSAS consists of two scales, the patient scale, which contains of six items, and the observer scale, which comprised five items. All items of the two scales are scored numerically. The patient scores the characteristics of scar color, pliability, thickness, relief, itching, and pain, whereas an observer scores scar vascularization, pigmentation, pliability, thickness, and relief (Figure 1,2) (4). The exclusion criteria were: 1) patients who were converted to laparotomy from laparoscopy, and 2) patients who had incision scars on their anterior abdominal wall. CLS was made with one 12-mm port for a 10-mm laparoscope and three 5-mm ports. MLS was

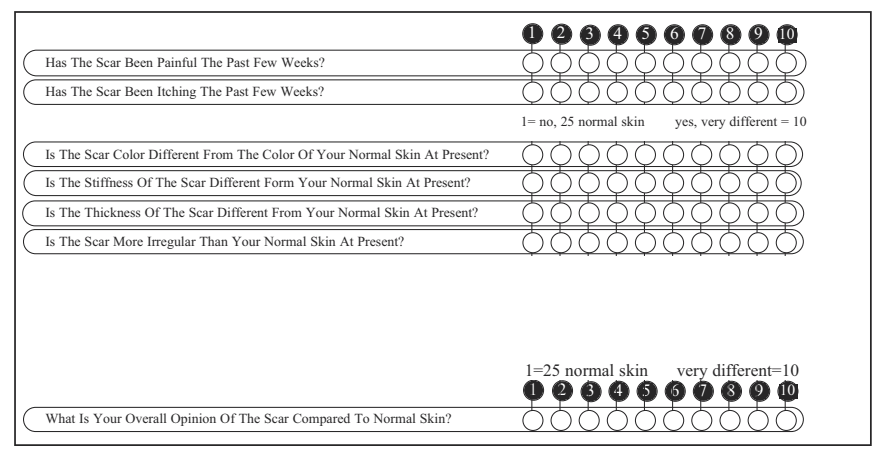

Figure 1: POSAS patient scale (6-60).

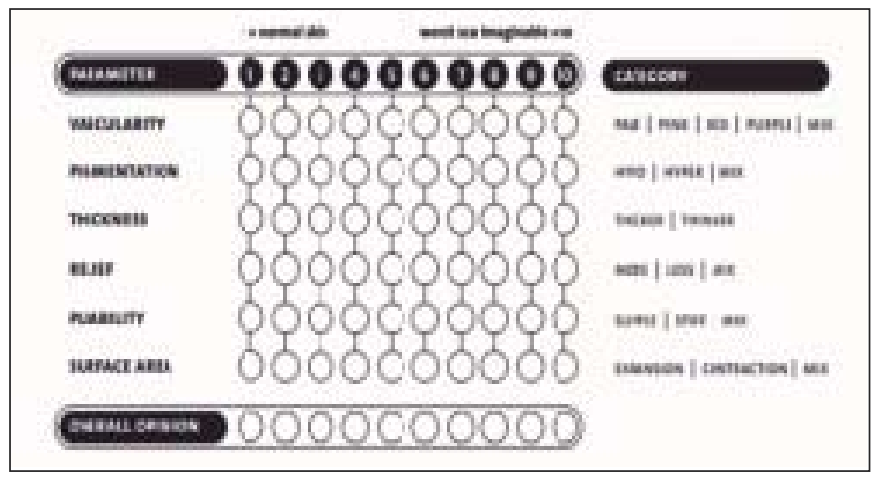

Figure 2: POSAS observer scale (5-50). made with one 5-mm port for a 5-mm laparoscope as well as two or three 3-mm ancillary trocars.

\section{Surgical methods}

Operative laparoscopy was performed under general anesthesia in all women. Bladder catheterization was performed for all patients. After the pneumoperitoneum was created using a Veress needle, a laparoscope (Karl Storz, Tuttlingen, Germany) was introduced through the umbilicus. Two 3-mm ancillary trocars were inserted under direct visualization in the lower abdomen. Following abdominal exploration, the patients were placed in the Trendelenburg position. A bipolar electrocoagulation device and cold scissors were used for tissue dissection. After insufflation of the abdomen and checking for bleeding, the operation was terminated. All patients were assessed by the same two physicians after at least three months for skin scar development. At the same time, all patients evaluated themselves regarding skin scar formation using the POSAS patient scale.

The main outcome measures were the surgical time of the procedures, estimated blood loss, preoperative and postoperative complications, and length of hospital stay between groups.

\section{Statistical analyses}

The IBM Statistical Package for the Social Sciences (SPSS) Version 22 was used for statistical analysis. The Chisquare test was used for categorical variables. Age, body mass index (BMI), operative time, blood loss, and hospital stay were compared using Student's t-test for independent groups. Non-parametric categorical variables were compared using the Chi-square test; continuous variables were analyzed using the Mann-Whitney $U$ test. The criterion for statistical significance was set at $p<0.05$ for all comparisons.

\section{Results}

The study included a total of 39 patients; 17 patients in the MLS group and 22 patients in the CLS group. Table 1 summarizes the comparison of a number of demographic features between the groups. The mean laparoscopic operation time was significantly shorter in the CLS group compared with the MLS group $(p<0.05)$. There was no difference between the two groups regarding blood loss (hematocrit changes) and length of hospital stay (Table 2). Both patient and observer POSAS scar scores were better in MLS group $(p<0.05)$ (Table 2$)$.

Table 1: Comparison of Demographic Features Between the Groups

\begin{tabular}{llll}
\hline Factors & MLS & CLS & $p$ value \\
\hline Age (years) (mean \pm SD) & $36.32 \pm 6.31$ & $37.26 \pm 9.10$ & 0.26 \\
Gravidity (median) (min - max) & $0.93(0-4)$ & $1.23(0-6)$ & 0.31 \\
Parity (median) (min - max) & $0.73(0-3)$ & $0.91(0-4)$ & 0.28 \\
BMI $\left(\mathrm{kg} / \mathrm{m}^{2}\right)$ (mean \pm SD) & $29.11 \pm 3.41$ & $27.19 \pm 4.40$ & 0.21 \\
\hline
\end{tabular}

BMI: Body mass index, CLS: Conventional laparoscopic surgery, MLS: Mini-laparoscopic surgery. SD: Standard deviation 
Table 2: Comparison of Operative Findings Between the Groups

\begin{tabular}{llll}
\hline Factors & MLS & CLS & $p$ value \\
\hline Blood loss (\%) (mean \pm SD) & $1.22 \pm 0.63$ & $1.31 \pm 0.81$ & 0.23 \\
Intraoperative complication & 0 & 0 & NA \\
Postoperative complication & 0 & 0 & NA \\
Operation time (min) (mean \pm SD & $43.32 \pm 7.63$ & $31.32 \pm 4.63$ & 0.04 \\
Length of hospital stay (days) (mean \pm SD) & $1.42 \pm 0.12$ & $2.02 \pm 0.32$ & 0.24 \\
Patient scar scale (mean \pm SD) & $15.7 \pm 6.6$ & $25.4 \pm 1.9$ & 0.02 \\
Observer scar scale (mean \pm SD) & $17.4 \pm 29.7$ & $26.4 \pm 22.9$ & 0.01 \\
\hline
\end{tabular}

CLS: conventional laparoscopic surgery; MLS: mini-laparoscopic surgery; SD: standard deviation

\section{Discussion}

In our study, the mean blood loss, complication rate, and mean length of hospital stay were similar in both groups. However, we found that operation time was longer in the MLS group. This is likely due to adaptation problems to surgical instruments in the beginning and lack of achievability to bipolar instruments in MLS that are commonly used in conventional laparoscopy for cutting and vessel stamping. As with all surgical procedures in minimally invasive surgery, the operation time may vary depending on several factors, such as physical characteristics of the patients (e.g., weight, surgical history). In the literature, there are not many publications related with MLS for surgical tubal sterilization. Literature studies for mini-laparoscopy are mostly about pediatric and general surgery. A study regarding MLS for benign gynecologic conditions in the literature described longer operation times $(5,6)$.

In the literature, there are studies comparing gasless, single-incision, and conventional laparoscopy for surgical sterilization $(7,8)$. However, to our knowledge, this study is the first to compare mini-laparoscopic and conventional laparoscopic surgical sterilization. We believe that our study has significance in this regard. One of the main advantages of MLS is the cosmetic result of the surgery. In the setting of general surgery, a meta-analysis has recently shown that mini-laparoscopy holds the advantage of eliciting a reduced level of wound pain compared with conventional laparoscopy, with better cosmetic results and decreased incisional hernia (9). Ghezziet et al. evaluated MLS in terms of hysterectomy and salpingoopherectomy in different studies and reported that was more advantageous $(10,11)$. Fanfani et al. reported that fewer ports and smaller port diameter were strongly related with less postoperative pain and requirement for analgesics (11). Ardovino et al. reported no difference in operation time and difficulty in surgery but they had better results regarding postoperative pain and cosmetic results (12). Although evaluating skin scar formation is challenging because of inadequate objective scales, the majority of studies in the literature demonstrated that cosmetic results were better after using smaller trocar sizes $(13,14)$. We used both patient and observer scar scales for the evaluation of scar formation. Both scores were better in the MLS group than in the CLS group. Nowadays, according to patient preferences, especially for young patients, the cosmetic results of surgery are almost as important as the treatment of the main pathology. However, we did not compare the groups in terms of post-surgical pain levels and amounts of additional analgesic use. In addition, long-term pain scores and the contraceptive efficacy of the procedure were not assessed in our study, which is the major limitation of our study.

By using mini-laparoscopy, it is possible to reduce subcutaneous or subfascial bleeding and hematoma formation (15). The other advantage of mini-laparoscopy is the reduction of the risk of postoperative hernia formation. It has been shown that $86.3 \%$ of all trocar hernias occur with $12 \mathrm{~mm}$ or larger trocars. Conversely, only $2.7 \%$ of all trocar hernias occur with 5 -mm trocars. In the present study, we observed no intraoperative complications in either group.

Some study limitations should be acknowledged such as the small sample size and retrospective design of the study. Moreover, we did not evaluate differences regarding the interval between the operation date and patient and observer scale assessment dates between two groups. Despite these restraints, to the best of our knowledge, this represents the first study to compare MLS versus CLS for tubal surgical sterilization

In conclusion, we feel that mini-laparoscopy surgery is a new promising technique and can be used for all gynecologic conditions performed with conventional laparoscopy as surgeons gain more experience.

:Acknowledgments: None

Source of funding: None

Conflict of interests: The authors declare that they have no conflict of interests.

\section{References}

1. ACOG: The American College of Obstetricians and Gynecologists, 2016, May, Available from https:// www.acog.org/-/media/For-Patients/faq035.contraception

2. Ghezzi F, Cromi A, Siesto G, Uccella S. Minilaparoscopic 
versus conventional laparoscopic hysterectomy: results of a randomized trial. J Minim Invasive Gynecol 2011 JulAug;18(4):455-61. doi: 10.1016/j.jmig.2011.03.019

3. Gagner M, Garcia-Ruiz A. Technical aspects of minimally invasive abdominal surgery performed with needlescopic instruments. Surg Laparosc Endosc 1998;8(3):171-9.

4. Draaijers LJ, Tempelman FR, Botman YA, Tuinebreijer WE, Middelkoop E, Kreis RW, et al. The patient and observer scar assessment scale: a reliable and feasible tool for scar evaluation. Plast Reconstr Surg 2004;113(7): 1960-5; discussion 1966-7.

5. Gencdal S, Aydogmus H, Aydogmus S, Kolsuz Z, Kelekci S. Mini-Laparoscopic Versus Conventional Laparoscopic Surgery for Benign Adnexal Masses. J Clin Med Res. 2017;9(7):613-617. doi: https://doi.org/10.14740/jocmr $3060 \mathrm{w}$

6. Gencdal S, Aydogmus H, Aydogmus S, Ekmekci E, Kolsuz Z. Mini-Laparoscopic Surgery for Gynecological Conditions. SciTz Gynecol Reprod Med. 2016;1(1):1001.

7. Ulker K, Huseyinoglu U. Comparison of tubal sterilization procedures performed by keyless abdominal rope-lifting surgery and conventional CO2 laparoscopy: a case controlled clinical study. ScientificWorldJournal 2013 Dec 24;2013:963615.doi:10.1155/2013/963615. eCollec tion 2013.

8. Guido RS, Brooks K, McKenzie R, Gruss J, Krohn MA. A randomized, prospective comparison of pain after gasless laparoscopy and traditional laparoscopy. J Minim Invasive Gynecol 1998;5(2):149-53.
9. Sajid MS, Khan MA, Ray K, Cheek E, Baig MK. Needlescopic versus laparoscopic cholecystectomy: a metaanalysis. ANZ J Surg 2009;79(6):437-42.

10. Ghezzi F, Uccella S, Casarin J, Cromi A. Microlaparoscopic bilateral adnexectomy: a 3-mm umbilical port and a pair of 2-mm ancillary trocars served as conduits. Am J Obstet Gynecol 2014;210(3):279 e271.

11. Fanfani F, Fagotti A, Rossitto C, Gagliardi ML. Laparoscopic, minilaparoscopic and single-port hysterectomy: perioperative outcomes. Surg Endosc 2012 Dec; 26(12):3592-6. doi: 10.1007/s00464-012-2377-2.

12. Ardovino M, Ardovino I, Castaldi MA, Trabucco E, Colacurci N, Cobellis L. Minilaparoscopic myomectomy: a mini-invasive technical variant. J Laparoendosc Adv Surg Tech A 2013;23(10):871-5.

13. Bisgaard T, Klarskov B, Trap R, Kehlet H, Rosenberg J. Microlaparoscopic vs conventional laparoscopic cholecystectomy: a prospective randomized double-blind trial. Surg Endosc. 2002;16(3):458-64.

14. Alponat A, Cubukcu A, Gonullu N, Canturk Z, Ozbay O. Is minisite cholecystectomy less traumatic? Prospective randomized study comparing minisite and conventional laparoscopic cholecystectomies. World J Surg 2002;26 (12):1437-40.

15. Nomura H, Okuda K, Saito N, Fujiyama F, Nakamura Y, Yamashita Y, et al. Mini-laparoscopic surgery versus conventional laparoscopic surgery for patients with endometriosis. J Minim Invasive Gynecol Gynecology and Minimally Invasive Therapy 2013;2(85): e88. 